\title{
Psikoedukasi Pendidikan Seks Remaja Dengan Gangguan Spektrum Autisme Untuk Meningkatkan Pengetahuan Tentang Pendidikan Seks Pada Orang tua dan Guru
}

\section{Psychoeducation On Sex Education To Improve Knowledge About Sex Education In Teens With Autism Spectrum Disorders To Parents And Teachers}

\author{
Doni Mustofa ${ }^{1}$, I.G.A.A. Noviekayati ${ }^{1}$, Sahat Saragih $^{1}$ \\ Universitas 17 Agustus 1945 Surabaya \\ dmdoni77@gmail.com
}

\begin{abstract}
Abstrak
Penelitian ini bertujuan untuk menguji efektifitas pemberian psikoedukasi pendidikan seks seks remaja dengan gangguan spectrum autis untuk meningkatkan pengetahuan tentang pendidikan pada orangtua dan guru. Serta menguji perbedaan pengetahuan orangtua dan guru tentang pendidikan seks setelah pemberian psikoedukasi pendidikan seks remaja dengan gangguan spektrum autis. Penelitian ini menggunakan jenis penelitian quasi experiment. Teknik analisis data yang digunakan dalam penelitian ini menggunakan uji statistik non parametrik versi SPSS 20, dengan Teknik Wilcoxon dan Mann Whitney $U$ Test. Subjek dari penelitian ini adalah orang tua yang mempunyai anak remaja dengan gangguan spektrum autis di Surabaya. Guru yang mengajar di sekolah menengah pertama inklusi di Surabaya. Total subjek dari penelitian ini berjumlah 30 subjek yang terdiri dari 15 subjek orangtua dan 15 subjek guru. Hasil Penelitian Z hitung $>$ Z tabel $=4.711>2.58$ yang menunjukkan bahwa psikoedukasi pendidikan seks remaja dengan gangguan spektrum autis efektif untuk meningkatkan pengetahuan tentang pendidikan seks orangtua dan guru. Sedangkan hipotesis kedua Z hitung $<\mathrm{Z}$ tabel $=0.334<1.96$ menunjukkan menunjukkan bahwa tidak terdapat perbedaan yang signifikan pengetahuan orang tua dan guru tentang pendidikan seks setelah mendapatkan psikoedukasi pendidikan seks remaja dengan gangguan spektrum autis.
\end{abstract}

Kata kunci: Psikoedukasi Pendidikan Seksual, Remaja Dengan Gangguan Spectrum Autis, Orangtua dan Guru

\begin{abstract}
The purpose of this study was to determine the effectiveness of psychoeducation on sex education in teens with autism spectrum disorders to improve knowledge about sex education to parents and teachers. And test the differences in the provision of psychoeducation for sex education to improve knowledge about sex education in teens with autism spectrum disorders between parents and teachers. This study use a type of quasi experiment research. The analysis data technique used in this study in the SPSS 20 version of the non-parametric statistical test, with the Wilcoxon Technique and the Mann Whitney U Test. The subjects of this study were parents who had teenagers with autism spectrum disorders in Surabaya. Teachers who teach in inclusive secondary schools in Surabaya. The total subjects of this study were 30 subjects consisting of 15 parent subjects and 15 teacher subjects. Research Results $Z$ count $>Z$ table $=4.711>2.58$ which indicates that the provision of psychoeducation for sex education to improve knowledge about sex education in teens with autism spectrum disorders to parents and teachers has a significant influence. While the second hypothesis $Z$ count $<Z$ table $=0.334<1.96$ shows that there is no significant difference in the provision of psychoeducation for sex education to improve knowledge about sex education in teens with autism spectrum disorders between parents and teachers.
\end{abstract}

Keyword : Psychoeducation On Sex Education, Teens With Autism Spectrum Disorders, Parents And Teachers 


\section{Pendahuluan}

Masa remaja adalah tahap peralihan dari masa anak-anak menuju masa dewasa. Masa remaja ini mengalami beberapa perubahan yang terjadi secara fisik, psikologis dan sosial. Tahap perkembangan remaja mulai dari ekplorasi diri, identitas peran, nilai dan perilaku. Sedangkan fisik remaja ditandai dengan perubahan pada fungsi fisiologis dan ciri fisik yang berhubungan dengan hormonal seksual (Kusmiran, 2013)

Pada remaja laki-laki akan mengalami perubahan fisik yang ditandai dengan beberapa hal seperti organ kelamin mulai menghasilkan sperma dalam testis, tumbuhnya kumis dan jenggot, jakun mulai tampak dan membesar, ereksi, suara berubah menjadi lebih besar dan berat, tumbuhnya rambut dibeberapa area seperti ketiak, kaki, organ kelamin dan kekuatan otot bertambah. Sedangkan pada perempuan perubahan fisik ini ditandai dengan beberapa hal seperti mulai menstruasi, suara lebih nyaring, mulai muncul jerawat, payudara mulai timbul membesar dan tumbuhnya rambut dibeberapa area seperti ketiak, organ kelamin (Batubara, 2010)

Perubahan fisik dan kematangan seksual adalah tahap tumbuh kembang yang terjadi selama alami dan terjadi pada remaja. Termasuk dengan remaja dengan gangguan spektrum autis juga mengalami perubahan fisik dan kematangan seksual yang sama dengan remaja pada umumnya. Karakteristik gangguan spektrum autis didefinisikan sebagai gangguan perkembangan dengan hambatan dalam komunikasi, perilaku, dan sosial. Remaja dengan gangguan spektrum autis memiliki hambatan dengan komunikasi, interaksi social dan aktivitas kegiatan sehari-hari serta memiliki ketertarikan pada sesuatu tertentu (APA, 2000)

Selanjutnya, ketika remaja dengan gangguan spektrum autis mengalami masa puber, mereka akan mengalami perubahan fisik, pertumbuhan serta perkembangan yang sama dengan anak normal lainnya dan menampakkan karakteristik seksual pada saat remaja (Pask, Hughes, \& Sutton, 2016). Akan tetapi, Sullivan dan Caterino (2008) menyebutkan bahwa perkembangan fisik anak dengan gangguan autisme tidak diiringi dengan perkembangan sosial dan emosi yang memadai, sehingga kondisi yang demikian membuat perkembangan seksual menjadi tantangan tersendiri bagi populasi tersebut, mengingat mereka tidak dapat memperoleh manfaat yang sama dari interaksinya dengan orang lain sebagaimana pembelajaran sosial yang diterima individu lain pada umumnya (Stokes, Newton, \& Kaur, 2007)

Dalam penelitian Wijaya (2010), Remaja dengan gangguan spektrum autis berperilaku yang tidak pantas tersebut termanifestasi dalam bentuk perilaku seperti, menyentuh bagian pribadi (vital) milik sendiri ataupun milik orang lain di depan umum (public area). Melepaskan celana di depan umum, melakukan masturbasi di sembarang tempat, adanya keinginan mencium pipi atau bibir orang lain tanpa izin, dan melepaskan pembalut ketika sedang menstruasi pada perempuan.

Menurut berita online nusabali.com 25 November 2018 mengunggah berita bertajuk "Pekak Diduga Lakukan Pelecehan Seksual Anak Autis" diberitakan bahwa kejadian di sebuah kebun pekak (kakek). Saksi kaget melihat korban bersama pekak (kakek). Di mana saat itu, posisi korban setengah nungging dengan celana belakang agak turun, dan posisi pekak (kakek) dalam keadaan berdiri dengan memasukkan tangan ke dalam celana pada bagian kemaluannya.

Kemudian menurut berita online kompas.com 29 Januari 2019 mengunggah berita bertajuk "Siswi Berkebutuhan Khusus Dicabuli Tetangganya di Sebuah Indekos di Surabaya” diberitakan bahwa kejadian terjadi di kamar mandi kos tersangka. Korban merupakan siswi berkebutuhan khusus kelas 1 SMP di salah satu sekolah di Surabaya. Korban dicabuli oleh tetangga kamar indekos dan tersangka melakukan perbuatannya sebanyak lima kali dalam sebulan, yakni sepanjang Januari 2019.

Peneliti melakukan studi pendahuluan berupa wawancara pada 6 Maret 2019 kepada orangtua yang memiliki remaja dengan gangguan spektrum autis dan guru di salah satu sekolah menengah pertama inklusi Surabaya. Terdapat dua orang responden yang memiliki remaja dengan gangguan spektrum autis dan satu orang responden tenaga pendidik. Menyatakan bahwa orangtua dan guru belum memahami mengenai seksualitas yang terjadi pada remaja dengan gangguan spektrum autis dan belum pernah 
mendapatkan informasi yang komprehensif mengenai seksualitas dan pendidikan seksual bagi remaja dengan gangguan spektrum autis.

Peran orangtua dalam memberikan pendidikan seksual kepada remaja autis tentunya bukan hal yang mudah, karena gangguan spektrum autis merupakan gangguan perkembangan yang salah satu cirinya adalah terdapat gangguan dalam berkomunikasi, sehingga jika memberikan pendidikan seksual memerlukan cara penyampaian yang baik agar mereka paham dan dapat mengaplikasikannya secara mandiri. Dalam hal pendidikan seksual pada remaja seringkali orangtua menyerahkan kepada pihak sekolah. Sedangkan dari literature banyak menyebutkan bahwa pendidiksn seksual di sekolah menunjukkan kurang efektif dan kurang cukup untuk memenuhi kebutuhan siswa yang berada di sekolah (Goldman, 2011). Hal tersebut diperkuat oleh argument dari Colarossi dkk (2014) menyatakan bahwa pendidikan seksual seharusnya dapat diberikan sejak dini dan melalui peran orangtua di dalam keluarga tersebut.

Di lingkungan sekolah remaja dengan gangguan spectrum autis sangat perlu membutuhkan penanganan dan perlakuan yang khusus. Banyak ditemukan permasalahan mengenai siapa yang akan memegang peranan yang lebih banyak dalam melakukan tugasnya terhadap siswa remaja dengan gangguan spectrum autis baik itu penanganan non akademik maupun akademik. Guru kelas biasanya bersikap acuh terhadap siswa remaja dengan gangguan spectrum autis karena sudah memiliki guru pendamping khusus dan shadow teacher.

Posisi guru berperan penting dalam memberikan pendidikan seksual kepada remaja dengan gangguan spektrum autis. Guru dan orangtua perlu bekerjasama untuk menyusun program belajar perilaku seksual secara terstruktur dan sistematis. Hal ini memiliki tujuan agar terciptanya suatu pembelajaran yang rutin perilaku seksual yang akan dilakukan oleh remaja dengan gangguan spektrum autis untuk mengelola hasratnya.

Berdasarkan uraian diatas, maka peneliti merasa perlu melakukan penelitian tentang pengetahuan pendidikan seks remaja dengan gangguan spektrum autis dengan cara memberikan psikoedukasi pendidikan seksual kepada orangtua yang memiliki anak remaja dengan gangguan spektrum autis dan guru sekolah inklusi.

Menurut Bloom, Engelhart, Furst, Hill, \& Krathwohl (1956), tujuan pendidikan yang paling umum adalah memperoleh pengetahuan atau informasi. Pendidikan dapat mengubah jumlah dan jenis pengetahuan yang dikuasai oleh seseorang. Pengetahuan melibatkan proses kompleks yang menjadikan seseorang dapat membuktikan sesuatu melalui proses mengingat, memanggil kembali, dan mengenali beberapa informasi, gagasan atau peristiwa berdasarkan pengalaman yang didapatkan melalui proses belajar. Bloom dan kawan-kawannya memunculkan konsep taksonomi bloom. Taksonomi Bloom adalah sebuak konsep tentang model hierarki yang digunakan untuk mengklasifikasikan perkembangan pendidikan secara objektif. Adapun klasifikasi taksonomi bloom adalah sebagai berikut:

1. Aspek kognitif merupakan kemampuan yang berkaitan dengan nalar atau proses berpikir untuk mengembangkan kemampuan rasional dan irasional. Aspek kognitif dibagi lagi menjadi beberapa aspek yaitu pengetahuan, pemahaman, penerapan, analisis, sintesis dan evaluasi.

2. Aspek afektif merupakan kemampuan yang mengutamakan perasaan, sikap, kepatuhan terhadap moral, minat dan sebagainya. Aspek afektif dibagi menjadi beberapa aspek yaitu penerimaan, responsif, penilaian, organisasi dan karakterisasi

3. Aspek psikomotor merupakan kawasan yang berkaitan dengan aspek-aspek keterampilan fisik. Aspek psikomotor dibagi menjadi beberapa aspek yaitu peniruan, penciptaan, kesiapan, respon tempat kompleks dan adaptasi

Krathwohl (2002) melakukan perbaikan Taksonomi Bloom dalam proses kognitif agar dapat digunakan dalam penilaian yang lebih fokus pada peningkatan kemampuan dalam belajar. Perbaikan taksonomi tersebut dilakukan dengan melakukan perubahan Taksonomi Bloom dari kata benda menjadi kata kerja. Perubahan dilakukan agar taksonomi bloom mencerminkan cara berpikir dalam suatu proses yang aktif. Kategori diubah menjadi kata kerja, kemudian menjadi beberapa subkategori mengalami perubahan. Proses kognitif tersebut adalah sebagai berikut:

a. Mengingat (Pengetahuan)

Mengingat didefinisikan sebagai proses untuk mendapatkan kembali informasi yang rasional dari memori jangka panjang. Mengingat meliputi proses mengenali dan memanggil kembali atau mengingat b. Memahami (Pemahaman) 
Memahami didefinisikan sebagai proses untuk menentukan makna pesan pembelajaran melalui lisan, tulisan, termasuk komunikasi grafis. Memahami meliputi proses menafsirkan, menerangkan dengan contoh, menggolongkan, merangkum, membandingkan, menyimpulkan dan menjelaskan

c. Menerapkan (Penerapan)

Menerapkan didefinisikan sebagai proses melakukan atau menggunakan suatu prosedur dalam situasi yang tertentu. Menerapkan termasuk proses melaksanakan dan menerapkan

d. Menganalisis (Analisis)

Menganalisis didefinisikan sebagai proses memecahkan ke materi ke dalam bagian utama serta mendeteksi bagaimana bagian tersebut saling berhubungan satu dengan yang lain dan keseluruhan dari bagian struktur. Menganalisis meliputi proses mengorganisir, membedakan dan menghubungkan e. Menilai (Penilaian)

Menilai didefinisikan sebagai proses membuat pertimbangan berdasarkan kriteria dan standar. Menilai meliputi proses memeriksa dan mengkritik

f. Menciptakan (Sintesis)

Menciptakan didefinisikan sebagai proses meletakan unsur - unsur secara bersama - sama untuk membentuk sesuatu yang baru, utuh dan padu, atau membuat suatu produk yang asli. Menciptakan meliputi proses menghasilkan, merencanakan, dan memproduksi

Autisme berasal dari kata "Autos" yang memiliki arti diri sendiri, sedangkan "Isme" yang memiliki arti suatu aliran. Autisme memiliki arti suatu aliran yang memiliki ketertarikan pada dunianya sendiri. Autistik adalah suatu jenis gangguan perkembangan yang kompleks menyangkut interaksi social, komunikasi dan aktivitas daya imajinasi. Menurut DSM V (APA, 2013), Karakteristik anak gangguan spektrum autis adalah sebagai berikut:

1. Memiliki komunikasi yang kurang dan interaksi sosial yang bersifat ajeg dalam berbagai hal atau konteks

a) Kurangnya hubungan komunikasi dan interaksi sosial emosi. Contohnya: pendekatan sosial yang tidak semestinya, tidak dapat melakukan komunikasi dua arah, kegagalan untuk merespon dan berinisiatif dalam interaksi sosial

b) Terhambatnya komunikasi non-verbal yang digunakan dalam berinteraksi sosial. Contohnya: hilangnya kontak mata, kurangnya menggunakan bahasa tubuh, kemampuan komunikasi verbal dan non-verbal yang tidak terintegrasi, dan ekspresi wajah

c) Kurang mampu mengembangkan, menjaga, dan memahami hubungan. Contohnya: sulit beradaptasi dalam berbagai konteks sosial, kesulitan dalam bermain imajinasi atau berteman, tidak memiliki ketertarikan terhadap teman sebaya

2. Pola perilaku, minat atau aktivitas yang terbatas, dan berulang, seperti yang ditunjukkan oleh minimal dua dari perilaku berikut:

a) Gerakan motorik yang berulang, menggunakan benda atau ucapan. Contohnya, gerakan sederhana yang berulang, mengantri mainan atau membalik benda, mengulang-ulang kata atau kalimat

b) Memiliki perhatian yang berlebihan pada kesamaan, rutinitas yang kaku atau pola perilaku vernal atau non-verbal Contohnya: rentan stress terhadap perubahan kecil, pola pikir yang kaku yang ditunjukkan dengan perilaku misalnya, makan makanan yang sama setiap hari, memilih rute yang sama

c) Memiliki minat atau ketertarikan yang tidak normal atau kelekatan yang tinggi. Contohnya, lekat dengan objek-objek tertentu

d) Hiperaktif atau hipoaktif terhadap sensori tertentu atau memiliki ketertarikan yang aneh pada lingkungan. Contohnya: bersikap tidak peduli dengan rasa sakit atau temperature suhu, respon yang berlawanan pada suara dan tekstur, penciuman yang berlebihan atau sentuhan dari objek. tertarik terhadap visual pada cahaya atau gerakan gerakan tertentu

3. Gejala-gejala harus muncul pada periode perkembangan awal (namun mungkin tidak terlihat sepenuhnya sampai tuntutan sosial melebihi kapasitas yang terbatas atau mungkin tertutupi dengan strategi belajar

4. Gejala-gejala tersebut menyebabkan hampatan pada area kehidupan sosial, pekerjaan, atau dalam lingkup kehidupan penting lainnya

5. Gangguan spectrum autis lebih baik tidak dijelaskan dengan gangguan hambatan intelektual atau keterlambatan perkembangan secara global. 
Penelitian ini bertujuan untuk: (1)untuk menguji efektifitas pemberian psikoedukasi pendidikan seks remaja dengan gangguan spectrum autis untuk meningkatkan pengetahuan tentang pendidikan seks pada orangtua dan guru, dan (2) menguji perbedaan pengetahuan orangtua dan guru tentang pendidikan seks setelah pemberian psikoedukasi pendidikan seks remaja dengan gangguan spektrum autis.

\section{Metode Penelitian}

Penelitian ini termasuk tipe penelitian kuantitatif. Penelitian kuantitatif adalah penelitian yang menekankan analisisnya pada data-data numerical yang akan diolah melalui metode statistik (Azwar, 2013). Pada penelitian ini menggunakan metode penelitian kuantitatif, dimana pada penelitian tersebut menekankan pada analisis yang berupa angka-angka kemudian diolah melalui metode statistik. Sedangkan jenis penelitian ini adalang jenis penelitian quasi eksperimen. Dalam penelitian eksperimen ini terdapat dua variabel yang digunakan, yaitu variabel bebas dan variabel terikat.

1. Variabel Terikat (Y) : Pengetahuan prantu dan guru tentang pendidikan seks remaja dengan gangguan spektrum autis

2. Variabel Bebas (X1) : Psikoedukasi pendidikan seks

3. Variabel Bebas (X2) : Orangtua yang mempunyai anak remaja dengan gangguan spektrum autis dan guru yang mengajar di sekolah menengah pertama inklusi di Surabaya

Definisi operasional pengetahuan tentang pendidikan seks pada remaja dengan gangguan spektrum autis adalah memperoleh pengetahuan atau informasi delapam kunci materi pendidikan skesual seperti : hubungan dengan orang lain, nilai-nilai seksualitas, memahami gender, tubuh dan perkembangan manusia, perilaku seksual, kesehatan seksual dan reproduksi. Sedangkan Definisi operasional Psikoedukasi pendidikan seks adalah kegiatan yang dilakukan untuk meningkatkan pemahaman, keterampilan dan pengetahuan tentang fungsi organ tubuh yang berkaitan dengan seksual sekaligus mengarahkan agar menyalurkan fungsi seksualnya tersebut dengan baik dan benar serta komitmen agar tidak terjadi penyalahgunaan organ reproduksi tersebut. Orangtua adalah ayah ibu kandung dalam satu rumah tangga. Orangtua memiliki peranan yang sangat penting dalam membesarkan dan merawat anak. Guru merupakan jabatan atau profesi yang memerlukan keahlian khusus sebagai guru. Pekerjaan ini tidak bisa dilakukan oleh orang yang tidak memiliki keahlian untuk melakukan kegiatan atau pekerjaan sebagai guru.

Jenis penelitian ini menggunakan jenis quasi eksperiment dengan metode eksperimen one group pretest postest design yaitu rancangan yang digunakan untuk satu kelompok diawali dengan diberikan pengukuran, lalu diberikan perlakuan dalam jangka waktu tertentu, kemudian dilakukan pengukuran untuk kedua kalinya (Suryabrata, 2014). Metode ini diberikan pada satu kelompok saja tanpa kelompok pembanding. Desain penelitian ini, kelompok diberi tes awal (pre-test) sebelum mendapatkan perlakuan untuk mengukur kondisi awal subjek penelitian dan kelompok diberi tes akhir (Post-Test) sesudah perlakuan untuk mengetahui kondisi akhir subjek penelitian.

Tabel 1. Desain Penelitian Quasi Eksperimen

\begin{tabular}{ccc}
\hline Pre Test & Perlakuan & Post Test \\
\hline O1 & $\mathrm{X}$ & O2
\end{tabular}

Keterangan:

O1 : Pretest terhadap subjek orangtua dan guru

$\mathrm{X} \quad$ : Treatment berupa pemberian psikoedukasi

O2 : Posttest terhadap subjek orangtua dan guru

Subjek dari penelitian ini adalah orang tua yang mempunyai anak remaja dengan gangguan spektrum autis di Surabaya. Guru yang mengajar di sekolah menengah pertama inklusi di Surabaya. Total subjek dari penelitian ini berjumlah 30 subjek yang terdiri dari 15 subjek orangtua dan 15 subjek guru. Adapun kriteria subjek penelitian (orangtua) sebagai berikut:

1. Memiliki anak remaja dengan gangguan spektrum autis.

2. Pendidikan terakhir minimal SMA.

3. Usia antara $35-47$ Tahun.

Sedangkan untuk kriteria subjek penelitian (guru) sebagai berikut:

1. Mengajar disekolah inklusi.

2. Termasuk guru reguler bukan guru pendamping khusus. 


\section{Usia Maksimal 56 Tahun}

Selain ditentukan dengan kriteria diatas pemilihan subjek melalui proses tahapan-tahapan tertentu. Adapun tahapan-tahapan yang dilakukan oleh peneliti sebagai berikut :

1. Subjek orangtua yang memiliki remaja dengan gangguan spektrum autis diberikan skala pengetahuan pendidikan seks remaja dengan gangguan spektrum autis sebanyak 15 subjek.

2. Subjek guru reguler yang mengajar disekolah inklusi diberikan skala pengetahuan pendidikan seks remaja dengan gangguan spektrum autis sebanyak 59 subjek.

3. Setelah diberikan skala pengetahuan pendidikan seks remaja dengan gangguan spektrum autis peneliti melakukan skoring dan mengkalisifikasikan nilai menjadi kategori tinggi, sedang dan rendah.

4. Dari hasil skala pengetahuan pendidikan seks remaja dengan gangguan spektrum autis yang diberikan psikoedukasi pendidikan seks untuk meningkatkan pengetahuan pendidikan seks remaja dengan gangguan spektrum autis adalah yang memiliki nilai kategori rendah dan sedang

\section{Hasil Penelitian}

Hipotesis pertama berbunyi ada efektifitas pemberian psikoedukasi pendidikan seks untuk meningkatkan pengetahuan tentang pendidikan seks remaja dengan gangguan spektrum autis kepada orangtua dan guru. Berdasarkan hasil uji Wilcoxon Signed Ranks Test pada tabel descriptive statistic terlihat bahwa data $(\mathrm{N})$ sebelum dan sesudah diberikan psikoedukasi sama-sama 30 subjek. Nilai ratarata (mean) pengetahuan pendidikan seks remaja dengan gangguan spektrum autis sebelum diberikan psikoedukasi $=11.47$, standart deviasi $=2.801$ dengan nilai mulai dari 7 sampai dengan 19 . Sedangkan nilai rata-rata (mean) pengetahuan pendidikan seks remaja dengan gangguan spektrum autis sesudah diberikan psikoedukasi $=22.27$, standart deviasi $=4.734$ dengan nilai mulai dari 12 sampai dengan 30 .

Tabel 2. Descriptive Statistics

\begin{tabular}{crrrrr}
\hline Perlakuan & N & Mean & Std. Deviation & Min & Max \\
\hline Sebelum Psikoedukasi & 30 & 11,47 & 2,801 & 7 & 19 \\
Sesudah Psikoedukasi & 30 & 22,27 & 4,734 & 12 & 30 \\
\hline
\end{tabular}

Berdasarkan pada tabel ranks dari total data $(\mathrm{N})=30$ terdapat 29 data dengan beda positif (positif ranks), tidak ada data dengan beda negatif dan terdapat satu data dengan perbedaan atau pasangan data sama nilainya (ties). Hal tersebut memiliki arti dari tigapuluh data yang dibandingkan menunjukkan tidak ada penurunan dari nilai hasil pretest ke nilai posttest. Disini terdapat 29 subjek yang mengalami peningkatan pengetahuan pendidikan seks remaja dengan gangguan spektrum autis dan terdapat 1 subjek yang memiliki nilai pretest dan posttest yang sama.

Tabel 3. Ranks

\begin{tabular}{llrcc}
\hline & & N & Mean Rank & Sum of Ranks \\
\hline & Neg Ranks & $0^{\mathrm{a}}$ &, 00 &, 00 \\
Sesudah Psikoedukasi - & Posi Ranks & $29^{\mathrm{b}}$ & 15,00 & 435,00 \\
Sebelum Psikoedukasi & Ties & $1^{\mathrm{c}}$ & & \\
& Total & 30 & & \\
\hline
\end{tabular}

Berdasarkan pada tabel test statistic terlihat bahwa nilai $\mathrm{Z}$ hitung sebesar $=4.711$ hal ini menunjukkan bahwa nilai $\mathrm{Z}$ hitung lebih besar dari $\mathrm{Z}$ tabel sebesar $=1.96$ dengan taraf signifikansi 5\% bahkan lebih besar dari Z tabel taraf signifikansi 1\% sebesar $=2.58$. Nilai Asymp.sig. (2 tailed) sebesar $=$ 0.000 lebih kecil dari pada 0.05 maka dapat disimpulkan bahwa hipotesis pertama diterima, artinya pemberian psikoedukasi pendidikan seks untuk meningkatkan pengetahuan tentang pendidikan seks remaja dengan gangguan spektrum autis kepada orangtua dan guru memberikan pengaruh yang signifikan. 


\begin{tabular}{lr}
\hline & Sesudah Psikoedukasi - Sebelum Psikoedukasi \\
\hline$Z$ & $-4,711^{\mathrm{b}}$ \\
Asymp. Sig. (2-tailed) & 000 \\
a. Wilcoxon Signed Ranks Test & \\
\hline
\end{tabular}

Hipotesis pertama berbunyi ada perbedaan pemberian psikoedukasi pendidikan seks untuk meningkatkan pengetahuan tentang pendidikan seks remaja dengan gangguan spektrum autis antara orangtua dan guru. Berdasarkan hasil uji Mann Whitney U Test pada tabel ranks terdapat 15 data dari orangtua dan 15 data dari guru. Mean rank untuk data psikoedukasi pendidikan seks remaja dengan gangguan spektrum autis terhadap orangtua sebesar $=14.97$ sedangkan Mean rank untuk data psikoedukasi pendidikan seks remaja dengan gangguan spektrum autis terhadap guru sebesar $=16.03$. Dengan masing-masing sum of rank untuk orangtua sebesar $=224.50$ dan untuk guru sebesar $=240.50$.

Berdasarkan mean rank untuk data psikoedukasi pendidikan seks remaja dengan gangguan spektrum autis terhadap guru lebih besar daripada mean rank untuk data psikoedukasi pendidikan seks remaja dengan gangguan spektrum autis terhadap orangtua $(16.03>14.97)$. Maka dilihat dari mean rank berarti pemberian psikoedukasi pendidikan seks remaja dengan gangguan spektrum autis terhadap guru cenderung lebih tinggi dibanding orangtua.

\begin{tabular}{llccc}
\multicolumn{5}{c}{ Tabel 5. Ranks } \\
\hline & Status & N & Mean Rank & Sum of Ranks \\
\hline \multirow{2}{*}{ Psikoedukasi } & Orangtua & 15 & 14,97 & 224,50 \\
Pendidikan Seks & Guru & 15 & 16,03 & 240,50 \\
& Total & 30 & & \\
\hline
\end{tabular}

Berdasarkan pada tabel test statistic terlihat bahwa nilai $\mathrm{Z}$ hitung sebesar $=0.334$ hal ini menunjukkan bahwa nilai $\mathrm{Z}$ hitung lebih kecil dari $\mathrm{Z}$ tabel sebesar $=2.58$ dengan taraf signifikansi $1 \%$ bahkan lebih kecil dari Z tabel taraf signifikansi 5\% sebesar $=1.96$. Nilai Asymp.sig. $(2$ tailed $)$ sebesar $=$ 0.738 lebih besar dari pada 0.05 maka dapat disimpulkan bahwa hipotesis kedua ditolak, artinya tidak terdapat perbedaan yang signifikan dalam pemberian psikoedukasi pendidikan seks untuk meningkatkan pengetahuan tentang pendidikan seks pada remaja dengan gangguan spektrum autis antara orangtua dan guru.

Tabel 6. Test Statistics ${ }^{\mathrm{a}}$

\begin{tabular}{lc}
\hline & Psikoedukasi Pendidikan Seks \\
\hline Mann-Whitney U & 104,500 \\
Wilcoxon W & 224,500 \\
Z &,- 334 \\
Asymp. Sig. (2-tailed) &, 738 \\
\hline
\end{tabular}

a. Grouping Variable: Status

\section{Pembahasan}

Berdasarkan hasil penelitian dilakukan oleh peneliti, diketahui bahwa pemberian psikoedukasi pendidikan seks remaja dengan gangguan spektrum autis efektif untuk meningkatkan pengetahuan tentang pendidikan seks orangtua dan guru. Sesuai dengan teori Bloom yang melibatkan proses kompleks sehingga menjadikan seseorang dapat membuktikan sesuatu melalui proses mengingat, memanggil kembali, dan mengenali beberapa informasi, gagasan atau peristiwa berdasarkan pengalaman yang didapatkan melalui proses belajar. Dengan proses pemberian psikoedukasi orangtua dan guru mampu meningkatkan pengetahuan tentang pendidikan seks remaja dengan gangguan spectrum autis. Oleh karena itu orangtua dan guru dapat memberikan pendidikan yang sesuai dengan remaja dengan gangguan spektrum autis. Setelah mendapatkan materi yang diberikan, orang tua dan guru menyadari pentingnya materi ini dan menganggap remaja dengan gangguan spektrum autis sama dengan remaja pada umumnya. Akan tetapi membutuhkan metode pembelajaran yang tepat sehingga remaja dengan gangguan spektrum autis paham apa yang akan diajarkan. 
Berdasarkan hasil penelitian diketahui bahwa tidak terdapat perbedaan yang signifikan pengetahuan orang tua dan guru tentang pendidikan seks setelah mendapatkan psikoedukasi pendidikan seks remaja dengan gangguan spektrum autis. Hal teresebut dimungkinkan karena beberapa hal. Pendapat Daradjat, (2012) orangtua merupakan orang pertama yang mendidik anak-anaknya, dari orangtua awal mula anak menerima pendidikan pertama kali. Hal ini menjadi bentuk pendidikan yang pertama dalam kelurga dan menjadi pendidik utama. Pada umumnya pendidikan didalam keluarga bukan berdasar dari kesadaran dan pengertian yang berasal dari pengetahuan, melainkan secara alamiah struktur dan terbentuknya membangun situasi pendidikan. Situasi pendidikan seks remaja dengan gangguan spektrum autis akan terwujud adanya hubungan dan pergaulan serta pengaruh timbal balik antara orangtua dan anak. Sedangkan peran guru dalam menangani remaja dengan gangguan spektrum autis dalam sekolah lebih ke pengetahuan pembelajaran akademik sesuai dengan keahlian guru tersebut.

Hal ini sesuai dengan penelitian dari Sari (2017) selama kegiatan pembelajaran dikelas guru reguler selalu mengarahkan, membimbing anak dengan gangguan spektrum autis saat mengerjakan pelajaran, tugas, bertingkah laku, kegiatan dalgkup sekolah dan berkomunikasi dengan teman. Dalam hal ini peran guru regular berperan sebagai guru pendamping khusus yakni memberikan layanan bagi siswa siswi dengan gangguan spektrum autis pada saat pelajaran seperti : 1) memaksimalkan komunikasi siswa-siswi dengan gangguan spektrum autis, 2) mengoptimalkan perilaku, sikap dan kebiasaan baik dengan cara melakukan pendampingan saat kegiatan belajar mengajar, 3) pendampingan siswa-siswi dengan gangguan spektrum autis pada saat mengerjakan soal, membaca, berhitung, menulis dan sebagainya, 4) memberikan motivasi dapat mengerjakan semua tugas dengan baik, 5) pendampingan siswa-siswi dengan gangguan spektrum autis pada saat ujian kenaikan kelas, 6) memberikan layanan pengulangan atau remidi

Orangtua memiliki peranan penting dan berpengaruh atas pendidikan anak-anaknya. Orangtua lebih mengerti tentang karakteristik anak dengan gangguan spectrum autis karena orangtua lebih dahulu mengetahui anaknya dan mengasuh anaknya mulai dari kecil. Subjek orangtua penelitian ini dilihat dari usianya cenderung lebih muda dibandingkan guru. Sehingga orangtua lebih mudah mengakses informasi dari media manapun seperti menggunakan media internet. Orangtua yang masih muda, tidak lagi canggung menggunakan alat komunikasi seperti handphone dan laptop, meskipun dari segi pendidikan terakhir orangtua adalah SMA.

\section{Kesimpulan}

Dalam penelitian ini dapat disimpulkan bahwa psikoedukasi pendidikan seks remaja dengan gangguan spektrum autis efektif dalam meningkatkan pengetahuan tentang pendidikan seks orangtua dan guru. Hasil penelitian yang kedua, menunjukkan bahwa tidak terdapat perbedaan yang signifikan pengetahuan orang tua dan guru tentang pendidikan seks setelah mendapatkan psikoedukasi pendidikan seks remaja dengan gangguan spektrum autis. Implikasi dari penelitian ini, orangtua dan guru yang mengikuti psikoedukasi pendidikan seks diharapkan untuk menyebarluaskan materi pendidikan seks remaja dengan gangguan spektrum autis kepada orangtua lain yang memiliki anak dengan gangguan spektrum autis dan guru yang mengajar di sekolah inklusi maupun sekolah luar biasa. Bagi peneliti selanjutnya yang ingin meneliti penelitian yang sama hendaknya memperhatikan variabel-variabel lain yang diduga mampu untuk meningkatkan pengetahuan pendidikan seks remaja dengan gangguan spektrum autis

\section{Daftar Pustaka}

American Psychiatric Association (APA). (2000). Diagnostic and Statistica Manual of Mental Disorders (DSM) IV-TR. Washington DC: American Psychiatric Association

American Psychiatric Association (APA). (2013). Diagnostic and Statistical Manual of Mental Disorders (DSM) V. Washington DC: American Psychiatric Association

Azwar. S. (2013). Metode Penelitian . Yogyakarta: Pustaka Pelajar

Batubara, J. R. L. (2010). Adolescent Development (Perkembangan Remaja). Sari Pediatri. Vol.12, No.1, $21-29$ 
Bloom, B. S., Engelhart, M. D., Furst, E. J., Hill, W. H., \& Krathwohl, D. R. (1956). Taxonomy of Educational Objective: The Classification of Educational Goals. Handbook 1 Cognitive Domain. New York: David McKay

Colarossi, L., Silver, E. J., Dean, R., Perez, A., \& Rivera, A. (2014). Adult role models: Feasibility, acceptability, and initial outcomes for sex education. American Journal of Sexuality Education, 9 (2), $155-175$

Daradjat, Z. (2012). Ilmu Pendidikan Islam, Cetakan X. Jakarta: Bumi Aksara

Goldman, J. D. (2011). An exploration in health education of an integrated theoretical basis for sexuality education pedagogies for young people. Health Education Research, 26 (3), 526-541

Kirkpatrick, D. L. (1996). Evaluating Training Programs. San Fransisco: Bereet Kohler Publiser

Krathwohl, D. R. (2002). A revision of Bloom's taxonomy: An overview. Theory into Practice. 41(4), 212-218

Kusmiran, E. (2013). Kesehatan Reproduksi Remaja Dan Wanita. Jakarta: Salemba Medika

Pask, L., Hughes, T. L., \& Sutton, L. R. (2016). Sexual knowledge acquisition and retention for individuals with autism. International Journal of School \& Educational Psychology, 4 (2), 86-94

Sari, A. N. I. (2017). Peran Guru Kelas Dalam Mengatasi Kesulitan Belajar Siswa Berkebutuhan Khusus (Autis) Di Kelas V SDN Merjosari 04 Kotta Malang. Skripsi, Fakultas ilmu tarbiyah dan keguruan, UIN Maulana Malik Ibrahim Malang

Sullivan, A., \& Caterino, L. C. (2008). Addresing the sexuality and sex education of individuals with autism spectrum disorder. Education and Treatment of Children, 31 (3), 381-394

Stokes, M., Newton, N., \& Kaur, A. (2007). Stalking, and social and romantic functioning among adolescents and adults with autism spectrum disorder. Journal of Autism and Developmental Disorder , 37 (10), 1969-1986

Wijaya, I. (2010). Pendidikan Pubertas bagi Individu Remaja dan Dewasa dengan Autisme. Bandung: Universitas Kristen Maranatha 